\title{
Antiguidade Tardia e a Islamização da Paisagem
}

Lygia Ferreira Rocco*

ROCCO, L. F. Antiguidade Tardia e a Islamização da Paisagem. R. Museu Arq. Etn., 32: 143-150, 2019.

Resumo: Os estudos sobre a Idade Média são na maioria das vezes analisados a partir da história do cristianismo, em que os estudos sobre o Islã são considerados uma área de investigação à parte, sendo que o Islão não entra como partícipe desse período, nem influencia os acontecimentos. As pesquisas desenvolvidas pela arqueologia islâmica colocam novas questões para as análises a respeito desse período a partir de uma história que não foi contada, mas que está presente na Idade Média em vários aspectos, inclusive em sua cultura material. Se a arqueologia medieval é uma disciplina nova, o interesse por uma arqueologia islâmica é mais recente, pois se deu a partir do final do século XIX. As novas evidências arqueológicas fornecem informações que questionam o que foi considerado até o momento a respeito das relações entre os diferentes grupos confessionais monoteístas, judeus, cristãos e muçulmanos, durante a Idade Média, no sentido eurocêntrico do termo, e abre novas perspectivas para uma história que foi deixada de lado. O texto busca esclarecer o emprego do termo medieval nos estudos da cultura islâmica, o histórico das pesquisas arqueológicas da mesma e a importância das investigações da arqueologia da paisagem para a mudança de paradigmas nas análises dos processos de islamização da paisagem ocorridos entre os séculos VII e XIII.

Palavras-chave: Islã; Idade Média; Arqueologia islâmica; Oriente Médio; História.

$\mathrm{O}$ sestudos sobre a Idade Média são na maioria das vezes analisados a partir da história do cristianismo, em que os estudos sobre o Islã são considerados uma área de investigação à parte, sendo que o Islão não entra

$\left.{ }^{*}\right)$ Mestre e doutora em Letras, no programa de Estudos Judaicos e Árabes pela Faculdade de Filosofia, Letras e Ciências Humanas, USP. Pesquisadora Associada do Laboratório de Arqueologia Romana Provincial, LARP-MAE/USP. <lyrocco@ gmail.com> como partícipe desse período, nem influencia os acontecimentos. Na maioria dos livros de história, esse período é considerado um dos causadores do fechamento da Europa em si mesma. Normalmente as abordagens sobre as sociedades islâmicas são tratadas como uma categoria monolítica, "quando na verdade [essas sociedades] são compostas de uma diversidade de identidades variáveis, como as que giram em torno da afiliação sectária, etnia (...)" (Insoll 2005:601). Nessa direção, a arqueologia islâmica desempenha um papel importante, pois coloca novas questões para as pesquisas relacionadas a 
esse período, a partir de uma história que não foi contada, mas que esteve presente na Idade Média em vários aspectos, inclusive em sua cultura material, em seus artefatos, em sua literatura, nas traduções de textos, e assim por diante.

Quando nos referimos à Europa desse período, não podemos deixar de considerar que a escrita da história acerca da idade média sempre teve uma grande fatia eurocêntrica. Essa história elaborada pelo Ocidente impõe às demais regiões do globo a sua visão de mundo quase que exclusivamente autocentrada, sendo aqui, bem otimista ao utilizar o "quase que exclusivamente".

Essa visão eurocêntrica é indicada em um texto de Trevo-Hoper citado por Goody em "O roubo da história":

"Os novos governantes do mundo, sejam lá quem forem, herdaram uma posição que foi construída pela Europa e somente pela Europa. São técnicas europeias, exemplos europeus, ideias europeias que arrancaram o mundo não-europeu de seu passado, alijando-o da barbárie da África, e das antigas, majestáticas e vagarosas civilizações da Ásia (...)". (Trevor-Hope 1965 apud Goody 2008:11).

Nessas abordagens, as relações de contato entre Oriente e Ocidente são na maioria das vezes excluídas nos estudos sobre os processos formadores da Europa. As investigações tocantes à Idade Média tratam quase exclusivamente sobre a Europa Ocidental, e quando ocorre alguma inserção das áreas islâmicas, a fazem de maneira bastante rápida, e frequentemente, não contextualizam o que ocorria nas regiões dominadas pelo Islã naquela mesma data.

Nesse ponto, também é necessário deixar claro o uso do termo "medieval" e "idade média”, criado pela historiografia ocidental, a qual localiza esse período entre os séculos V e XV, sendo a divisão clássica da história ocidental. Para esse mesmo período de tempo, o medieval europeu equivaleria ao período clássico islâmico, o qual corresponde às datas entre 632 a 1453, morte do profeta Muhammad e a conquista de Constantinopla pelos Otomanos, respectivamente. Para esses estudiosos, a partir do ponto de vista oriental, não existe um Islã medieval.

Logo, o adjetivo "medieval" quando empregado ao Islã no período equivalente ao europeu, nos conduz a alguns problemas; um deles é excluir o Oriente e suas contribuições e contatos no processo formativo da Europa Ocidental, o outro é reforçar a dicotomia entre Oriente e Ocidente. O "Islã Medieval" é um termo apropriado da historiografia europeia para ao mesmo tempo inclui-lo e exclui-lo. Inclui por sua invasão nas terras europeias, por ser um dos elementos responsáveis do fechamento da Europa em si mesma, e o excluí da formação desse mesmo Ocidente que impôs suas ideias ao resto dos povos, e é visto como sendo o espaço e a civilização formadora do mundo moderno.

A cronologia dos estudos dos diferentes povos do mundo é baseada nessa periodização eurocêntrica, a qual tem o monopólio dos períodos históricos cuja crença é a de uma era dourada, no caso, a Antiguidade Clássica, e uma ideia de futuro baseada no progresso. Nesse caso, voltando a Goody (2008), a construção de uma história unificada, necessita de uma periodização unificada, portanto, a adoção de termos pode ter sentido para uns, mas não para outros, como no caso "Idade Média". A concepção de uma genealogia sociocultural europeia coloca tudo o que não é Europa como atrasado. Mas foi a ascensão do Islã, segundo esse mesmo historiador, o turning point da Europa, que teria deslocado o centro de gravidade do poder europeu de Roma para o norte da Europa (Pirenne 2010).

Se por um lado, as margens do Mediterrâneo deixaram de ser possessão de Bizâncio e ou da Roma do Ocidente, essas mesmas margens passaram a ser parte do grande lago muçulmano (Braudel 1988). Essa "troca de mãos" não ocasionou um fim do tráfego marinho e das trocas comerciais, como afirmam alguns historiadores, ao contrário, durante $\mathrm{o}$ primeiro período da expansão islâmica, e no decorrer dos séculos posteriores, ocorreu uma intensa fusão de culturas (Braudel 1989), do Oceano Atlântico ao norte da China. E, ao redor do Mediterrâneo, essa situação fez com que toda essa região sob a expansão muçulmana se comportasse de maneira similar à da Antigui- 
dade, ou seja, como uma ponte onde trafegaram correntes de pensamentos e culturas de distintas regiões. Esse também foi um momento de forte urbanização e de fundação de novas cidades.

No tocante à arqueologia medieval, se esta é considerada uma disciplina nova, o interesse pela arqueologia islâmica é bem mais recente, surgiu no final do século XIX, embora o interesse recaísse mais no interesse pela estética de seus edifícios e dos objetos produzidos que em suas sociedades (Petersen 2005:100), mas foi apenas na segunda metade do século XX que os estudos avançaram em outras direções. A arqueologia islâmica é uma área em expansão, com projetos de escavação e estudos que vão desde a Península Ibéria até Ásia Central, da África subsaariana até o subcontinente indiano (Milwright 2006:1).

As evidências arqueológicas colocam novas questões para o que foi considerado até o momento no que foi afirmado quanto às relações entre muçulmanos e cristãos, muçulmanos e judeus durante a Idade Média e abrem novas perspectivas para uma história que durante muito tempo foi deixada de lado a partir da perspectiva ocidental.

Qualquer discussão sobre a antiguidade tardia e a islamização da paisagem já é em si um grande desafio, pois a expansão do Islã nos 100 anos após a morte do profeta Muhammad apresenta ao pesquisador um amplo campo de análise devido à grande área geográfica que ocupou. São os mais diversificados tipos de assentamentos sobre os quais a nova comunidade construiu suas edificações. Muitos dos assentamentos islâmicos estão sobre ruínas gregas, romanas, bizantinas e, devemos assinalar que nas terras onde o Islã surgiu já existiam assentamentos de diversos povos: das sociedades da Mesopotâmia, sumérios, hititas, fenícios, nabateus, sassânidas e também de outras regiões, como os egípcios, coptas etc. (boone \& benco 1999:51-71; Almutairi 2011).

"A grande extensão geográfica conquistada pelo Islã produziu uma multiplicidade de formas e empréstimos e, ao mesmo tempo, devido à facilidade de ir e vir das pessoas e, às novas conquistas, forjou-se uma certa unificação na linguagem. (...)
As regiões que estiveram sob o domínio de algum governo islâmico, mesmo por um curto período, reconhecem na sua paisagem elementos que podemos denominar por 'islâmicos"” (Rocco 2014:3-5).

Como podemos observar, é um grande montante de informação e de regiões, porque Arqueologia Islâmica não se refere nem a um período específico, nem a uma região geográfica em particular, pois o centro do 'mundo islâmico' mudou muitas vezes ao longo do tempo (Walker 2014). Da mesma maneira, não é definida por uma única metodologia ou constructo teórico, pois "islâmico" não é equivalente ao que é "arqueologia bíblica", que enfatiza o estudo dos locais e personagens mencionados nos textos religiosos. O termo "islâmico" se refere aos estudos arqueológicos das sociedades e comunidades islâmicas, e das regiões que estavam sob o domínio de um governo muçulmano, onde quer que elas fossem encontradas (Grabar 1987). Pode ser considerado um tipo de arqueologia "histórica", em que o estudo de sociedades historicamente - textualmente conhecidas pode ser investigado através de uma combinação de "textos e fala".

No caso da arqueologia islâmica, as atividades e o interesse dos pesquisadores desde o início estiveram fortemente vinculados à expansão colonial dos países europeus, e, embora os estratos islâmicos fossem, com muita frequência, encontrados durante as escavações dos mais variados sítios, essas camadas foram ordinariamente negligenciadas, de maneira a muitas vezes provocar a sua destruição de forma irreversível. Durante as diversas escavações empreendidas pelas expedições de estudo, a descoberta de evidências arqueológicas de civilizações antigas, no caso, a Antiguidade clássica e anteriores, encobriu qualquer interesse em relação à história islâmica que acabava por ser sempre omitida. Soma-se a isso, a sempre ameaça de nações islâmicas sobre a Europa desde o surgimento do Islã até o enfraquecimento do Império otomano no século XIX.

Sob a influência das ideias positivistas de Comte, passa a ser elaborado um entendimento do surgimento e desenvolvimento da civilização 
islâmica considerando o papel histórico do islamismo, que passa também a pertencer à fase "medieval" do desenvolvimento da humanidade, entendendo por humanidade, a europeia. Com essa abordagem, também os estudos das religiões passam a ser analisados através do método comparativo.

Essas novas atitudes inspiraram as escolas orientalistas que surgiram no final do século XIX e podemos ver nos estudos de Alfred von Kremer e do austríaco Aloys Sprenger, quem escreveu entre outros títulos, A vida de Muhammad (1851). Kremer foi um dos que lançaram as bases para os estudos do Islã e de sua cultura material. Em 1850, ele iniciou um levantamento do tecido urbano da cidade de Damasco e seus monumentos históricos, tendo resultado na publicação, em 1855, de Topographie von Damascus.

O avanço russo em direção à Ásia, a partir de 1850, colaborou para o desenvolvimento dos estudos sobre o Islã, sendo que a escavação realizada em Samarqand em 1885 foi considerada a primeira em um sítio islâmico.

Vernoit (1997) comenta que na primeira metade do século XX estavam sendo publicados pela primeira vez os manuais de arte e arquitetura islâmica os quais apresentavam uma mudança de terminologia. Temos então o Manuel D'Art Musulman (1907) de Henri Saladin, e a mudança de paradigmas nos estudos de arte e arquitetura islâmica passaram do estudo a partir de raças para o estudo de culturas. Essa mudança ainda é gradativa na disciplina e confirma as noções de que não houve um domínio de uma cultura árabe, mas sim de uma construção coletiva e lenta de árabes, persas, berberes, turcos, e demais povos que habitavam as regiões que foram dominadas pelos muçulmanos.

A expansão islâmica que marcou os séculos VII ao IX, tanto pela sua natureza como pela sua extensa expansão territorial, do extremo da Ásia Oriental até a costa africana do Oceano Atlântico, representou uma mudança com relação às tradições locais, mas hoje não poderíamos afirmar que seria uma ruptura radical, mas sim transformações de tradições locais, transformações que podem ser percebidas na produção da cultura material de uma vasta área, e que podem ser detectadas na arquitetura, no urbanismo, nos artefatos, na dieta, entre outros elementos.

Entre os registros da cultura material nos quais podemos perceber a extensão desses contatos, estão os da numismática. Aqui podemos ter uma ideia dos contatos entre os grupos muçulmanos para além das fronteiras do Islã. Entre os séculos VIII e X, encontramos moedas no oeste da Rússia e na Escandinávia que permitem identificar a existência de uma rede de comércio de longa distância. Marcus Milwright (2006) cita a grande distribuição geográfica onde a moeda islâmica é encontrada: são encontrados dirhams do século IX nas regiões da Rússia europeia, entre o Mar Negro e o Mar Báltico, e uma grande quantidade na Escandinávia: 80.000 na Suécia, 400 na Noruega, 1.700 na Finlândia, 5.000 na Dinamarca. No norte da Inglaterra também foi encontrada uma boa quantidade de moedas islâmicas. E esse número representa apenas uma pequena fração do que foi produzido na época.

Novas evidências arqueológicas apresentam os contatos que os muçulmanos tiveram em outras regiões, são as sepulturas localizadas na França. Essas evidências encontradas em escavações recentes, por volta de 2010, são consideradas as primeiras evidências arqueológicas e antropológicas da presença islâmica na França, e datam aproximadamente do século VII.

Outros estudos que recorrem à cunhagem de moedas e que usam as datas da arqueologia islâmica para tratar do comércio de tecidos e metal realizado entre as regiões muçulmanas e a Europa antes do século XII, foram feitos por Maurice Lombard (apud Vernoit 1997:8) na década de 1970, e fornecem novos paradigmas para se pensar esse período na Europa medieval, assim como os monumentos encontrados na região da Normandia, e os elementos utilizados no Batistério de Florença, analisado por Andrea Piccini (2009).

A islamização da paisagem também passa pelo interesse que os estudos do Islã possam ter em determinadas regiões. Para o significado de paisagem, devemos considerar diferentes abordagens, cuja discussão foge do escopo deste texto, mas cabe comentar aqui que para o 
termo paisagem, “(...) uma variedade de referências paisagísticas é usada, ora enfatizando um aspecto natural (ecológico; geomorfológico ou hidrológico, por exemplo), ora um cultural (tecnológico; organizacional ou cosmológico) do ambiente humano" (Kormikiari 2000:3)

Retomando às discussões sobre antiguidade (clássica) e idade média, segundo algumas vertentes de pesquisas, as regiões que estavam dominadas pelo Império Romano foram agrupadas pelo Império Romano em uma estrutura cultural, social e política homogênea, e cujos elementos foram adotados e assimilados pelos germanos. Estudos mais recentes sobre a romanização, como os de Louise Revell, Sarah Cormack, Clifford Ando, mostram que os processos de romanização foram muito mais complexos e heterogêneos e, ao mesmo tempo em que o Império provocava a romanização, ele também se orientalizava e em um momento posterior, se germanizava, neste último, nos referimos às regiões europeias.

Oriente Médio foi a região onde duas potências de mesma intensidade se defrontaram, Roma e Pérsia (Rocco 2008). Durante o Império do Oriente, os reinos anexados a Roma eram regiões bastante sofisticadas. A Síria, a Anatólia e a Palestina em algumas épocas estavam sob o domínio romano, em outras sob o domínio parta. A retração do império romano do Oriente se inicia a partir do terceiro século de dominação e culmina com a expansão dos árabes muçulmanos no século VII.

O mesmo se deu após o surgimento e a expansão do Islã. A paisagem passa a ser islamizada, como do momento da expansão islâmica, após a morte de Muhammad em 362 EC, quando ocorreram a tomada de Ifrikiyah, atual Tunísia (639 EC) e, em 641 EC, a fundação de Fusțāt, construída sobre um antigo forte romano e embrião da atual cidade do Cairo no Egito.

No século VII, e a partir da conquista da Península Ibérica pelos muçulmanos no século VIII, a cultura material, entre ela, a arquitetura, desenvolveu uma nova linguagem que conjugou elementos de diversas regiões e o diálogo entre as culturas, da Europa ocidental, do Magrebe e Norte da África e do Oriente Médio, se intensificou na mesma proporção da velocidade com que o Islã se expandiu.

\section{Neste sentido:}

“(...) a abordagem da paisagem é relevante para o objetivo de a Arqueologia explicar o passado humano por meio de sua habilidade em reconhecer e avaliar as relações interdependentes e dinâmicas que as pessoas mantêm com as dimensões física, social e cultural de seus meio-ambientes ao longo do tempo e do espaço”. (Kormikiari 2000:4).

Embora se considere que o nomadismo seria o modo de vida dominante das comunidades da península arábica, é importante salientar que nem todos eles eram nômades, e as comunidades nômades desempenharam um papel importante no desenvolvimento social, cultural e artístico dos povos pré-islâmicos e islâmicos, pois colocavam em contato e foram responsáveis pela transmissão de conhecimento entre os pontos mais distantes dessa vasta região. Por outro lado, as comunidades sedentárias participaram ativamente no processo político dessa região durante a história.

A heterogeneidade é outro aspecto que tem que ser apontado quanto às construções urbanas. Com as conquistas árabes, os povos se arabizavam, ou seja, passavam a se expressar na língua árabe, mas as construções são múltiplas, pois ocorreram em diferentes meios, povos e condições. Devemos, portanto, considerar, na verdade, essas conquistas como uma elaboração coletiva de diversos povos: árabes, turcos, berberes, persas, coptas, judeus, africanos, indianos, chineses islamizados (ou não), e o que dava unidade a tamanha diversidade foram basicamente dois elementos: a religião islâmica e a língua árabe.

A religião islâmica atuou como um fator de organização externa de uma ampla área geográfica, e que configurou, adaptando-se à realidade e culturas locais, as leis e formas de organização social, proporcionou a coesão cultural de uma vasta e heterogênea região. E a língua serviu como elemento de comunicação e intercomunicação entre os diferentes povos.

Se concebemos as paisagens como formações dinâmicas, logo, a cidade, considerada a construção de um grupo, é "um produto de fatores culturais e ambientais e uma expressão 
do modo de vida de um povo para o qual se constrói." (Rocco 2008: 3). A distribuição dos espaços na planta de um edifício ou em uma cidade é o resultado das relações sociais que são organizadas de maneira a distinguir os lugares, primeiro através da linguagem, pela toponímia e, depois, através dos espaços construídos.

Embora o Islã não prescreva conceitos arquitetônicos formais, a reza diária fornece uma série de elementos que, em consequência, geram a necessidade de padrões físicos para os seus seguidores. Essa reza deve ser realizada tanto individualmente como coletivamente, e deve ser orientada para Meca, o que gera implicações espaciais que estruturam o desenho do edifício religioso, a mesquita.

A Islamização da paisagem é uma realidade, embora os estudos sobre o tema e a ampliação do conhecimento sobre a islamização da paisagem também estejam sujeitos ao interesse que os estudos do Islã possam ter em determinadas regiões e sua relação, tanto na Europa, como nos continentes africano e asiático.

$\mathrm{Na}$ Península Ibérica, os estudos a respeito do processo de islamização buscam entender a transformação de um povo herdeiro da tradição romana [através do reino visigótico] em andaluzes de quem as fontes escritas informam desde os séculos IX e X (López 2008). No Egito, a islamização se deu desde o primeiro século, logo após a morte de Muhammad, com a fundação de Fusțāt, como comentando anteriormente.

Na Palestina, os estudos desenvolvidos por Katia Cytryn-Silverman buscam entender o processo de islamização de Tiberias, cidade na região da Galileia, a qual foi importante centro de poder durante os primeiros séculos após o surgimento do Islã.

Tiberias foi fundada por Herode Antipas, filho de Herodes o Grande entre os anos de $18 \mathrm{e}$ 20 EC. No século III floresceu o status de colônia romana e depois tornou-se a capital do povo judeu, centro do desenvolvimento do Talmude palestino. Durante todo o período inicial do Islã, dos séculos VII ao X, a cidade continuou a desenvolver suas yeshivat (escolas rabínicas) ao mesmo tempo em que a cidade se expandia como cidade islâmica, sob os governos omíadas, abássidas, fatímidas e aiúbidas. A conquista árabe da cidade se deu logo no início do Islã, em 635 EC.
Várias mesquitas foram construídas no local, sendo que as escavações da mesquita principal, ou da Sexta-feira, estão sob a coordenação de Cyntryn-Silverman. A área está construída sobre várias camadas temporais, romana, bizantina, são encontrados restos de cruzados e de sinagogas e igrejas cristãs. A expansão de Tiberias é semelhante à de outras regiões que possuíam estruturas romanas e bizantinas durante o período islâmico. Entre Bizâncio e o Islão existiu intensa troca de elementos materiais, tanto os bizantinos adotaram o gosto pelos objetos orientais, como os árabes muçulmanos procuraram utilizar as técnicas artísticas bizantinas.

Várias são as cidades da antiga Palestina que podem auxiliar na construção a respeito da compreensão dos processos de islamização do território. $\mathrm{O}$ caso de Tiberias é um importante exemplo, sendo que a cidade já era proeminente desde os romanos. A análise dessa dinâmica de ocupação do espaço é um importante instrumento para que se possa entender como se deu a islamização da paisagem da cidade, sua expansão e como era a relação entre os diferentes grupos confessionais.

Nessa direção também podemos mencionar o caso de outro edifício confessional, não islâmico, na organização do espaço urbano no interior da cidade predominantemente islâmica. O caso da sinagoga de Ben Ezrá na cidade do Cairo, no Egito, demonstra como um edifício não islâmico pôde servir de elemento organizador do espaço no processo de desenvolvimento da paisagem urbana, e como as "comunidades confessionais não ficaram isoladas no seu próprio meio" (Rocco 2014: 238).

Os estudos que apontam caminhos para a compreensão da urbanização das regiões conquistadas pelos muçulmanos entre os séculos VII e XIII permitem que se rompa o paradigma de isolamento cultural de grupos e de diferentes comunidades. A partir das escavações desenvolvidas nas áreas conquistadas podemos analisar como se deu a islamização da paisagem e o papel que edifícios simbólicos exercem neste processo, agindo ao mesmo tempo como elemento organizador e de demonstração de novo poder político. Para autores como Casal et al. (2006 apud Gutiérrez 2015), a possibilidade de uma relação 
entre a implantação de mesquitas em uma determinada área urbana e o programa de islamização promovido pelo Estado deve ser examinada com mais detalhes para entender esse processo em toda a sua complexidade, inclusive na Europa.

ROCCO, L. F. Late Antiquity and the Islamization of the Landscape. R. Museu Arq. Etn., 32: 143-150, 2019.

\begin{abstract}
Studies on the Middle Ages are most often analyzed from the history of Christianity, in which Islam is considered a separate area of inquiry. The research developed by Islamic archeology raises new questions for the analysis of this period from a history that has not been told, but which is present in the Middle Ages in several aspects, including in its material culture. If medieval archeology is a new discipline, the interest in an Islamic archeology is more recent, since it took place from the end of the nineteenth century. The new archeological evidence provides information that questions what has been considered up to now regarding relations between the different monotheistic religion groups, Jewish, Christian and Muslim during the Middle Ages, in its Eurocentric sense of the term, and opens up new perspectives for a history which was left aside. The text seeks to clarify the use of the medieval term in the studies of Islamic culture, the history of the archaeological researches of the same area and the importance of the investigations of the landscape archeology for the paradigm shift in the analysis of the processes of Islamization of the landscape occurred between the VIIth and XIIth centuries.
\end{abstract}

Keywords: Islam; Middle Age; Islamic Archaeology; Middle East; History.

\title{
Referências bibliográficas
}

Almutairi, M. 2011. The Archaeology of Kuwait. PhD. These. School of History and Archaeology, Cardiff University.

Ando, C. 2000. Imperial Ideology and Provincial Loyalty in the Roman Empire. University of California Press, California.

Braudel, F. 1988. Os Homens e a Herança no Mediterrâneo. Editora Martins Fontes, São Paulo.

Braudel, F. 1989. Gramática das Civilizações. Editora Martins Fontes, São Paulo.

Boone, J. L.; Beno, N. L. 1999. Islamic Settlement in North Africa and the Iberian Peninsula. Annual Review of Anthropology, vol. 28: 51-71. JSTOR, www.jstor.org/stable/223388

Cormack, S. 2004. The Space of Death in Roman Asia Minor. Phoibos, Viena.
Cytryn-Silverman, K. 2009. The Umayyad Mosque of Tiberias. In: Muqarnas: An Annual on the Visual Culture of the Islamic World XXVI. Brill, Leiden: 37-61.

Goody, J. 2008. O Roubo da História. Como Europeus se Apropriaram das Ideias e Invenções do Oriente. Editora Contexto, São Paulo.

Grabar, O. 1987. The Formation of Islamic Art. Yale University Press, Yale, New Haven.

Gutiérrez, C. González. 2015. Secondary Mosques in Madinat Qurtuba: Islamization and Suburban Development through Minor Religious Spaces. Papers from the Institute of Archaeology, 25: 2: 1-18, DOI: http://dx.doi.org/10.5334/pia.479

Kormikiari, M. C. N. 2000. Arqueologia da paisagem. Labeca/MAE/USP. Disponível em: http://labe- 
ca.mae.usp.br/media/filer_public/2014/07/16/ kormikiari_arqueologia_paisagem.pdf

Kremer, A. F. von 1855. Topographie von Damaskus. Zeitschr. D. K. Akad. D. Wissensch, vol VI: 56 páginas. Disponível em : http://digital.bib-bvb.de/ view/bvb_single/single.jsp?dvs=1561595240255 121\&locale=pt_BR\&VIEWER_URL=/view/ bvb_single/single.jsp?\&DELIVERY_RULE_ ID $=39 \&$ bfe $=$ view/action $/$ singleViewer.do?dvs= $\&$ frameId=1\&usePid $1=$ true $\&$ usePid $2=$ true

López, J. C. C. 2008. Islamization in al-Andalus through Archaeology. The case of the "vega" of Granada. Disponivel em: http://www.arqueologiamedieval.com/articulos/96/islamization-in-al-andalus-through-archaeology-the-case-of-the-quot-vega-quot-of-granada Acesso em maio/2018.

Insoll, T. 2005. Archaeology and Islamic identities in Bahrain. Antiquity, 79: 601

Milwright, M. 2006. Defining Islamic Archaeology: Some Preliminary Notes. Aga Khan Program in Harvard University: 1.

Petersen, A. 2005. What is 'Islamic' archaeology?" Antiquity, 79:100.

Piccini, A. 2009. Arquitetura do Oriente Médio ao Ocidente: A transferência de elementos arquitetônicos através do Mediterrâneo até Florença. AnnaBlume, São Paulo.

Pirenne, H. 2010. Maomé e Carlos Magno. O Impacto do Islã Sobre a Civilização Europeia. Editora Contraponto, Rio de Janeiro.

Revell, L. 2009. Roman imperialism and local identities. New York: Cambridge University Press, Cambridge, New York.
Rocco, L. F. 2008. A mesquita de Ibn Tülün como representação da herança arquitetônica árabe: estudo da Mesquita de Ibn Tülün como monumento-síntese das características árabes e das transferências de elementos arquitetônicos entre os povos não árabes. Dissertação de Mestrado. Faculdade de Filosofia, Letras e Ciências Humanas, Universidade de São Paulo, São Paulo. 2008. Doi: 10.11606/D.8.2009.tde23042009-122942.

Rocco, L. F. 2014. Diálogos da arquitetura no Cairo entre os séculos X e XIII: a sinagoga de Ben Ezrá e o contexto da cidade islâmica. Tese (Doutorado em Estudos Judaicos) - Faculdade de Filosofia, Letras e Ciências Humanas, Universidade de São Paulo, São Paulo. doi:10.11606/T.8.2014.tde-08102014-182152. Acesso em: maio/2018.

Saladin, H. 1907. Manuel D'Art Musulman. Librairie Alphonse Picard et Fils, Paris.Disponível em: https://archive.org/details/manueldartmusulm00sala/page/n10 Acesso: maio/2018.

Sprenger, A. 1851. Life of Mohammad from Original Sources. Presbyterian Mission Press, Allahabad.

Vernoit, S. 1997. The Rise of Islamic Archaeology. Muqarnas, Vol. 14: 1-10, Brill, Leiden. Disponível em: https://www.jstor.org/stable/1523232.

Walker, B. J. 2014. Introduction to the Journal of Islamic Archaeology Journal of Islamic Archaeology, vol 1, n. 1. Disponivel em: https:// www.scienceopen.com/collection/515ba6e386b3-4ec7-ac2d-d09516cf94b7 Acesso em: maio/2018. 